\title{
OPEN Fetal abdominal overgrowth is already present at $20-24$ gestational weeks prior to diagnosis of gestational diabetes mellitus
}

\author{
Wonjin Kim $\circledast^{1,2,4}$, Soo Kyung Park $\oplus^{3,4}$ \& Yoo Lee Kim $\oplus^{1 \otimes}$ \\ Fetal abdominal obesity (FAO) was detected at the time of gestational diabetes mellitus (GDM) \\ diagnosis at 24-28 gestational weeks (GW) in older ( $\geq 35$ years) and/or obese ( $\geq$ body mass index \\ $25 \mathrm{~kg} / \mathrm{m}^{2}$ ) women and persisted until delivery. We investigated whether FAO is already present at \\ 20-24 GW. Medical records of 7820 singleton pregnancy including 384 GDM were reviewed. Fetal \\ abdominal overgrowth was assessed by the fetal abdominal overgrowth ratios (FAORs) of the \\ ultrasonographically estimated gestational age (GA) of abdominal circumference per actual GA by \\ the last menstruation period, biparietal diameter or femur length, respectively. FAO was defined as \\ FAOR $\geq 90$ th percentile. FAORs measured at $20-24 \mathrm{GW}$ in older and/or obese but not in young and non- \\ obese GDM subjects were significantly higher than those in NGT subjects. Relative to NGT subjects \\ without FAO at 20-24 GW, odds ratios for exhibiting FAO at GDM diagnosis and large for gestational \\ age in GDM with FAO at 20-24 GW were 10.15 and 5.57, and their primary cesarean delivery rate \\ was significantly higher than those in GDM without FAO (44\% vs. $29 \%$ ). Earlier diagnosis and active \\ interventions of GDM well before 20-24 GW might be necessary to prevent FAO in the older and/or \\ obese women.
}

Childhood obesity is increasing worldwide with the incidence of type 2 diabetes in adolescents ${ }^{1-3}$. Gestational diabetes mellitus (GDM) is a risk factor for childhood obesity in offspring. Although management of GDM reduced the rate of large for gestational age (LGA) and macrosomia, it did not fully normalize neonatal outcomes, including the rates of neonatal hypoglycemia, raised cord blood C-peptide levels ${ }^{4,5}$. Furthermore, no reduction in childhood obesity or metabolic dysfunction in the offspring of treated GDM subjects has been reported, even though only female offspring showed significantly lower fasting glucose $e^{6,7}$. This controversial situation raises the question whether the onset of fetal overgrowth among women subsequently diagnosed with GDM might occur well before the diagnosis of GDM at $\leq 28$ gestational weeks $(\mathrm{GW})$. Sovio et al. reported that diagnosis of GDM was preceded by fetal abdominal obesity (FAO) between 20-28 GW, and its effect on FAO was additive with the effect of maternal obesity ${ }^{8}$. A prospective cohort study that investigates fetal growth by ultrasonography revealed that fetus of GDM subjects started to show larger estimated fetal weight (EFW) at $20 \mathrm{GW}$ and became statistically significant at $28 \mathrm{GW}$ and showed smaller HC (head circumference)/AC (abdominal circumference) ratio in the later pregnancy ${ }^{9}$.

Venkataraman et al. observed a 'thin but fat' phenotype, that is disproportionate increase in adiposity despite smaller or similar lean body mass, in the fetus of GDM mother even at $20 \mathrm{GW}$, predating the biochemical diagnosis of $\mathrm{GDM}^{10}$. The link between maternal glucose level and neonatal adiposity has been confirmed, and the relationship was suggested to be mediated by fetal insulin production ${ }^{11-13}$. Thus, FAO is mainly caused by fetal hyperinsulinemia together with excess maternal fuel. As fetal hyperinsulinemia as early as $14-16 \mathrm{GW}$ was

\footnotetext{
${ }^{1}$ Division of Endocrinology and Metabolism, Department of Internal Medicine, CHA Gangnam Medical Center, CHA University School of Medicine, 566, Nonhyeon-ro, Gangnam-gu, Seoul 06135, Republic of Korea. ${ }^{2}$ Yonsei University College of Medicine, Seoul, Republic of Korea. ${ }^{3}$ Department of Biostatistics and Data Science, University of Texas Health Science Center at Houston, Houston, TX 77030, USA. ${ }^{4}$ These authors contributed equally: Wonjin Kim and Soo Kyung Park. ${ }^{\circledR}$ email: ylkim@cha.ac.kr
} 
observed in the fetus of mother with diabetes, much earlier diagnosis and intervention than the current diagnosis of GDM at 24-28 GW might be necessary to prevent fetal obesity and macrosomia ${ }^{13}$.

According to Brunetti et al.s Italian study ${ }^{14}$, early GDM screening at $16-18 \mathrm{GW}$ in high risk women ${ }^{15}$ reduced $\mathrm{AC}$ and EFW measured at $20.6 \mathrm{GW}$ and led to reduced infant birth weight, and these parameters were all comparable with those in low and medium risk GDM and NGT subject screened late. Also, AC and EFW percentile in medium and low risk group were significantly higher than those in NGT group but there was no significant difference in birth weight percentile ${ }^{16}$.

We previously reported that FAO is already present at diagnosis of GDM at $24-28 \mathrm{GW}$ in the older ( $\geq 35$ years) and/or obese $\left(\mathrm{BMI} \geq 25 \mathrm{~kg} / \mathrm{m}^{2}\right)$ GDM subjects but not in young and non-obese GDM subjects ${ }^{17}$. These findings suggest that while screening and diagnosis of GDM at $24-28 \mathrm{GW}$ is not late for young ( $<35$ years) and non-obese $\left(\mathrm{BMI}<25 \mathrm{~kg} / \mathrm{m}^{2}\right)$ women, much earlier diagnosis and intervention might be necessary in the older and/or obese women to prevent FAO resulting from fetal hyperinsulinemia.

In this study, we investigated whether FAO is already present at 20-24 GW in GDM mother in order to determine the appropriate time for early diagnosis and treatment of GDM to prevent FAO.

\section{Results}

Clinical and biochemical characteristics and pregnancy outcomes of the normal glucose tolerance and GDM subjects according to maternal age and pre-pregnancy BMI. As we previously reported $^{18}$, maternal age and pre-pregnancy BMI were significantly higher in patients with GDM, but weight gain until diagnosis of GDM was not higher as compared with normal glucose tolerance (NGT) subjects.

$\mathrm{HbA1c}$ measured at diagnosis was significantly higher in the obese group 2 and 4 GDM than in the non-obese group 1 and 3 GDM. There was a significantly higher frequency of insulin treatment during pregnancy in the obese group 2 and 4 compared with the young and non-obese group $1 \mathrm{GDM}(17.4 \%$ and $15.7 \%$ vs. 8.2\%, $p<0.05)$.

The prevalence of LGA at birth $(12.7 \%$ vs. $5.1 \%, p<0.05)$, macrosomia ( $4.5 \%$ vs. $1.9 \%, p<0.05)$, and primary cesarean delivery rates $(30.2 \%$ vs. $22.5 \%, p<0.05)$ were significantly higher in the GDM patients than in the NGT subjects. In the subgroup analysis, as compared with NGT subjects, all GDM subgroups had a higher prevalence of LGA at birth and macrosomia, but young and non-obese group 1 GDM did not (Table 1, published in Ref. $\left.{ }^{15}\right)^{18}$.

Results of fetal biometry and fetal abdominal overgrowth ratios (FAORs) in the NGT, GDM, and GDM subgroups. While actual gestational age (GA) determined by last menstrual period (LMP) and estimated GA of biparietal diameter (BPD) and femur length (FL), and EFW by ultrasonography done at 20-24 GW, 4 weeks prior to screening with 50-g glucose tolerance test (GCT), were similar among study groups, estimated GA of AC was significantly higher in total GDM and older and non-obese group 3 GDM subjects than those in NGT subjects (Table 2).

All fetal abdominal overgrowth ratios (FAORs) of total GDM subjects were significantly higher than those of NGT subjects. In subgroup analysis, FAOR of GA-AC/GA-LMP in group 2, 3, and 4 GDM, GA-AC/GA-BPD in group $2 \mathrm{GDM}$, and GA-AC/GA-FL in group $3 \mathrm{GDM}$ were significantly higher than those in NGT subjects. However, all FAORs of young and non-obese group 1 GDM subjects were not significantly different from those of NGT subjects (Table 2).

According to investigation of the birth characteristics of those without fetal biometry data, there was no significant difference among GDM subjects but NGT subjects without fetal biometry dada showed lower rate of LGA at birth and primary cesarean delivery. Thus, we suggest, especially for GDM subjects, the current pregnancy outcome data presented in Table 1 were not biased by the availability of fetal biometry data (Supplementary Table S1).

Odds ratios for FAO in NGT, GDM and GDM subgroups. Relative to NGT subjects, odds ratio for FAO indicated by GA-AC/GA-LMP $\geq 90$ th percentile and GA-AC/GA-FL $\geq 90$ th percentile in total GDM subjects was 1.496 (95\% CI 1.097-2.038) and 1.589 (1.171-2.156), respectively (Supplementary Table S2).

In group $1 \mathrm{GDM}$ subjects, odd ratios for FAO by all FAORs were not significantly higher than those in NGT group. On the other hand, odds ratios for FAO were 3.915 (1.500-10.233) in group 2 GDM, as indicated by FAOR of GA-AC/GA-BPD and $2.151(1.037-4461)$ in group 4 GDM by GA-AC/GA-FL. Odds ratios for FAO in group 3 GDM was $2.041(1.244-3.098)$ by FAOR of GA-AC/GA-LMP and $1.637(1.043-2.568)$ by GA-AC/ GA-FL (Supplementary Table S2).

FAORs and odds ratios for FAO according to GW in NGT and GDM subjects. The FAOR of GA-AC/GA-LMP in GDM subjects was not significantly higher than those of NGT at $20 \mathrm{GW}$, but those became significantly higher at 21 and $22 \mathrm{GW}$ and this tendency maintained until $23 \mathrm{GW}$ (Table 3). Also, odds ratio for FAO in the GDM subjects was significantly increased relative to that of NGT subjects at 21 GW. But EFW of GDM subjects tended to higher than EFT of NGT subjects without significance (Supplementary Table S3).

Clinical characteristics and pregnancy outcomes of GDM and NGT subjects based on presence or absence of FAO at 20-24 GW. Comparing with the FAO (-) groups, maternal age of the FAO (+) groups was significantly higher in both NGT and GDM subjects, but pre-pregnancy BMI and weight gain until diagnosis of GDM of the FAO (+) groups were significantly higher in NGT but not in GDM subjects.

While fasting plasma glucose on 100-g oral glucose tolerance test (OGTT), HbAlc and HOMA- $\beta$ (homeostatic model assessment for insulin resistance) of the $\mathrm{FAO}(+)$ groups were not significantly different from those of the FAO (-) groups in both NGT and GDM subjects, HOMA-IR (homeostatic model assessment for insulin secretion) of the FAO (+) group was significantly lower than those of the FAO (-) group in GDM but not in 


\begin{tabular}{|c|c|c|c|c|c|c|}
\hline & \multirow[b]{2}{*}{ NGT $(n=6721)$} & \multirow{2}{*}{$\begin{array}{l}\text { Total GDM } \\
(\mathbf{n}=378)\end{array}$} & \multicolumn{4}{|l|}{ GDM } \\
\hline & & & Group $1(n=144)$ & Group $2(n=22)$ & Group $3(n=162)$ & Group $4(n=50)$ \\
\hline \multicolumn{7}{|c|}{ Clinical and biochemical } \\
\hline Age (years) & $33.1 \pm 3.8$ & $35.3 \pm 4.0^{\mathrm{a}}$ & $31.7 \pm 1.7^{\mathrm{a}}$ & $31.4 \pm 2.2$ & $38.0 \pm 2.6^{\mathrm{a}, \mathrm{b}, \mathrm{c}}$ & $38.6 \pm 2.6^{\mathrm{a}, \mathrm{b}, \mathrm{c}}$ \\
\hline $\begin{array}{l}\text { Pre-pregnancy } \\
\text { BMI }\left(\mathrm{kg} / \mathrm{m}^{2}\right)\end{array}$ & $20.6 \pm 2.6$ & $22.3 \pm 3.5^{\mathrm{a}}$ & $20.6 \pm 2.0$ & $28.0 \pm 2.8^{\mathrm{a}, \mathrm{b}}$ & $21.3 \pm 2.0^{\mathrm{a}, \mathrm{c}}$ & $28.0 \pm 2.4^{\mathrm{a}, \mathrm{b}, \mathrm{d}}$ \\
\hline \multicolumn{7}{|l|}{ Weight gain $(\mathrm{kg})$} \\
\hline $\begin{array}{l}\text { Pre-pregnancy- } \\
\text { at diagnosis }\end{array}$ & $7.6 \pm 3.2$ & $7.8 \pm 3.6$ & $8.3 \pm 3.7$ & $6.7 \pm 4.3^{\mathrm{a}}$ & $8.0 \pm 3.4$ & $6.9 \pm 3.4^{\mathrm{a}}$ \\
\hline $\begin{array}{l}\text { Pre-pregnancy- } \\
\text { near term }\end{array}$ & $13.0 \pm 4.1$ & $11.5 \pm 4.6^{\mathrm{a}}$ & $12.2 \pm 4.5$ & $9.3 \pm 6.4^{\mathrm{a}, \mathrm{b}}$ & $11.7 \pm 4.1^{\mathrm{a}}$ & $9.5 \pm 4.8^{\mathrm{a}, \mathrm{b}}$ \\
\hline $\begin{array}{l}50-\mathrm{g} \text { GCT } \\
(\mathrm{mmol} / \mathrm{L})\end{array}$ & $6.2 \pm 1.2$ & $9.2 \pm 1.4^{\mathrm{a}}$ & $9.0 \pm 1.1^{\mathrm{a}}$ & $9.6 \pm 1.4^{\mathrm{a}}$ & $9.1 \pm 1.1^{\mathrm{a}}$ & $9.6 \pm 2.4^{\mathrm{a}}$ \\
\hline \begin{tabular}{|l|}
$\begin{array}{l}\text { Fasting plasma } \\
\text { glucose }^{\mathrm{f}}(\mathrm{mmol} / \mathrm{L})\end{array}$ \\
\end{tabular} & $4.5 \pm 0.4$ & $5.0 \pm 0.8^{\mathrm{a}}$ & $4.8 \pm 0.6^{\mathrm{a}}$ & $5.5 \pm 0.9^{\mathrm{a}, \mathrm{b}}$ & $4.9 \pm 0.6^{\mathrm{a}, \mathrm{c}}$ & $5.3 \pm 1.5^{\mathrm{a}, \mathrm{b}, \mathrm{d}}$ \\
\hline $\begin{array}{l}\text { HbAlc at } \\
\text { diagnosis }^{\mathrm{f}}(\%)\end{array}$ & $5.0 \pm 0.3$ & $5.3 \pm 0.5^{\mathrm{a}}$ & $5.2 \pm 0.3^{\mathrm{a}}$ & $5.6 \pm 0.6^{\mathrm{a}, \mathrm{b}}$ & $5.2 \pm 0.3^{\mathrm{a}, \mathrm{c}}$ & $5.6 \pm 1.0^{\mathrm{a}, \mathrm{b}, \mathrm{d}}$ \\
\hline $\begin{array}{l}\begin{array}{l}\text { HbAlc at } \\
\text { diagnosis } \\
(\mathrm{mmol} / \mathrm{mol})\end{array} \\
\text { (mmol }\end{array}$ & $31.3 \pm 3.5$ & $34.4 \pm 6.0$ & $33.4 \pm 4.1$ & $37.6 \pm 6.9$ & $33.9 \pm 4.1$ & $38.6 \pm 10.8$ \\
\hline $\begin{array}{l}\text { Fasting insulin }{ }^{\mathrm{f}} \\
(\mathrm{pmol} / \mathrm{L})\end{array}$ & $54.9 \pm 29.2$ & $68.8 \pm 34.7^{\mathrm{a}}$ & $65.3 \pm 34.8$ & $111.8 \pm 35.4^{\mathrm{a}, \mathrm{b}}$ & $60.4 \pm 26.4^{c}$ & $88.2 \pm 32.6^{\mathrm{a}, \mathrm{b}, \mathrm{c}, \mathrm{d}}$ \\
\hline $\begin{array}{l}\text { Insulin treatment } \\
(\%)\end{array}$ & - & 10.4 & 8.2 & $17.4^{\mathrm{b}}$ & 9.8 & $15.7^{\mathrm{b}}$ \\
\hline \multicolumn{7}{|l|}{ Pregnancy outcomes } \\
\hline Primipara (\%) & 70.2 & 66.7 & 77.1 & 81.8 & $59.9^{\mathrm{a}}$ & $52.0^{\mathrm{a}}$ \\
\hline $\begin{array}{l}\text { Cesarean delivery } \\
(\%)\end{array}$ & 33.9 & $46.8^{\mathrm{a}}$ & 30.6 & 40.9 & $58.6^{\mathrm{a}}$ & $58.0^{\mathrm{a}}$ \\
\hline \begin{tabular}{|l|}
$\begin{array}{l}\text { Primary cesarean } \\
\text { delivery }(\%)\end{array}$ \\
\end{tabular} & 22.5 & $30.2^{\mathrm{a}}$ & 22.9 & 36.4 & $35.8^{\mathrm{a}}$ & 30.0 \\
\hline $\begin{array}{l}\text { Infant birth weight } \\
\text { (g) }\end{array}$ & $3197 \pm 421$ & $3226 \pm 510$ & $3157 \pm 487$ & $3303 \pm 677^{b}$ & $3262 \pm 452^{\mathrm{a}, \mathrm{b}}$ & $3265 \pm 654$ \\
\hline $\begin{array}{l}\text { GA at delivery } \\
\text { (weeks) }\end{array}$ & $39.0 \pm 1.5$ & $38.4 \pm 1.8^{\mathrm{a}}$ & $38.5 \pm 1.8^{\mathrm{a}}$ & $38.2 \pm 2.2^{\mathrm{a}}$ & $38.5 \pm 1.5^{\mathrm{a}}$ & $37.8 \pm 2.4^{\mathrm{a}}$ \\
\hline LGA (\%) & 5.1 & $12.7^{\mathrm{a}}$ & 7.6 & $18.2^{\mathrm{a}}$ & $14.2^{\mathrm{a}}$ & $20.0^{\mathrm{a}}$ \\
\hline $\operatorname{Macrosomia}^{\mathrm{e}}(\%)$ & 1.9 & $4.5^{\mathrm{a}}$ & 3.5 & 4.5 & $4.3^{\mathrm{a}}$ & $8.0^{\mathrm{a}}$ \\
\hline
\end{tabular}

Table 1. Clinical and biochemical characteristics and pregnancy outcomes of NGT and GDM subjects according to maternal age and pre-pregnancy BMI. NGT normal glucose tolerance, GDM gestational diabetes mellitus, $B M I$ body mass index, GCT glucose challenge test, $H b A 1 c$ glycosylated hemoglobin, GA gestational age, $L G A$ large for gestational age; GDM group 1 (age $<35$ years and $\mathrm{BMI}<25 \mathrm{~kg} / \mathrm{m}^{2}$ ); group 2 (age $<35$ years and $\mathrm{BMI} \geq 25 \mathrm{~kg} / \mathrm{m}^{2}$ ); group 3 (age $\geq 35$ years and $\mathrm{BMI}<25 \mathrm{~kg} / \mathrm{m}^{2}$ ); group 4 (age $\geq 35$ years and $\mathrm{BMI} \geq 25 \mathrm{~kg} /$ $\left.\mathrm{m}^{2}\right)$. ${ }^{\mathrm{a}} \mathrm{p}<0.05$, compared with NGT, ${ }^{\mathrm{b}} \mathrm{p}<0.05$, compared with GDM group $1,{ }^{\mathrm{c}} \mathrm{p}<0.05$, compared with GDM group 2, ${ }^{\mathrm{d}} \mathrm{p}<0.05$, compared with GDM group 3 , ${ }^{\mathrm{e}}$ Infant birth weight $\geq 4 \mathrm{~kg}$, ${ }^{\mathrm{f}} \mathrm{Column}$ Ns for the variable are different from the Ns presented in the table.

NGT subjects. With HOMA-IR, GDM subjects showed significantly higher values than NGT subjects only in FAO ( $(-)$ groups $(2.3 \pm 1.2$ vs. $1.6 \pm 0.9, \mathrm{p}<0.05)$ but not in FAO $(+)$ groups $(1.9 \pm 0.9$ vs. $1.4 \pm 0.7, p>0.05)$. With HOMA- $\beta$, GDM subjects showed lower values than NGT subjects in FAO (+) groups (153.6 \pm 142.6 vs. $213.2 \pm 167.5, \mathrm{p}>0.05)$ without significance whereas those in FAO $(-)$ groups were comparable with each other $(157.2 \pm 89.1$ vs. $172.1 \pm 92.3, \mathrm{p}>0.05)$.

The frequency of FAO at diagnosis of GDM was significantly higher in the FAO (+) group than in the FAO $(-)$ group in both NGT and GDM subjects. While male sex and primary cesarean delivery rate of the FAO (+) groups were significantly higher than those of the FAO (-) groups in both NGT and GDM subjects, the frequency of primipara, LGA at birth, and macrosomia of the FAO (+) groups were significantly higher than those of the FAO (-) groups in NGT but not in GDM subjects (Table 4).

Odds ratios for FAO at the time of GDM diagnosis, being LGA at birth, and macrosomia. Relative to the FAO (-) NGT subjects at 20-24 GW, FAO (+) NGT subjects revealed odds ratios for exhibiting FAO at diagnosis of GDM, LGA at birth, and macrosomia as 4.56 (95\% CI 3.63-5.74), 3.5 (2.68-4.59), and 2.68 (1.73-4.14), respectively.

While FAO (-) GDM subjects at 20-24 GW showed odds ratios for exhibiting FAO at diagnosis of GDM 2.03 (1.39-2.97), LGA at birth, 3.10 (2.14-4.51), and macrosomia, $2.96(1.67-5.26)$ relative to FAO (-) NGT subjects, FAO (+) GDM subjects at 20-24 GW showed markedly high odds ratios for FAO at diagnosis of GDM 10.15 and LGA at birth 5.57, but not the ratio for macrosomia (Table 5). 


\begin{tabular}{|c|c|c|c|c|c|c|}
\hline & \multirow[b]{2}{*}{ NGT $(n=6639)$} & \multirow{2}{*}{$\begin{array}{l}\text { Total GDM } \\
(\mathbf{n}=357)\end{array}$} & \multicolumn{4}{|l|}{ GDM } \\
\hline & & & Group $1(n=135)$ & Group $2(n=20)$ & Group $3(n=154)$ & Group $4(n=48)$ \\
\hline \multicolumn{7}{|l|}{ Fetal biometry } \\
\hline GA-LMPa & $22.1 \pm 0.9$ & $22.1 \pm 0.9$ & $22.1 \pm 0.9$ & $21.9 \pm 1.0$ & $22.1 \pm 0.9$ & $22.0 \pm 0.8$ \\
\hline GA-AC (week) & $22.7 \pm 1.1$ & $22.9 \pm 1.1^{\mathrm{b}}$ & $22.8 \pm 1.1$ & $23.0 \pm 1.3$ & $22.9 \pm 1.2^{\mathrm{b}}$ & $22.8 \pm 1.0$ \\
\hline GA-BPD (week) & $22.4 \pm 1.2$ & $22.4 \pm 1.1$ & $22.4 \pm 1.2$ & $22.1 \pm 1.5$ & $22.5 \pm 1.1$ & $22.4 \pm 0.9$ \\
\hline GA-FL (week) & $22.2 \pm 1.1$ & $22.2 \pm 1.1$ & $22.2 \pm 1.2$ & $22.1 \pm 1.3$ & $22.2 \pm 1.1$ & $22.2 \pm 1.0$ \\
\hline EFW (g) & $515.5 \pm 93.0$ & $519.7 \pm 91.3$ & $515.3 \pm 89.9$ & $514.8 \pm 120.8$ & $524.9 \pm 92.3$ & $517.4 \pm 79.4$ \\
\hline \multicolumn{7}{|l|}{ FAOR } \\
\hline GA-AC/GA-LMPa & $1.027 \pm 0.037$ & $1.034 \pm 0.038^{c}$ & $1.029 \pm 0.035$ & $1.046 \pm 0.027^{\mathrm{b}}$ & $1.036 \pm 0.041^{\mathrm{b}}$ & $1.037 \pm 0.037^{\mathrm{b}}$ \\
\hline GA-AC/GA-BPD & $1.013 \pm 0.043$ & $1.019 \pm 0.043^{\mathrm{b}}$ & $1.017 \pm 0.044$ & $1.039 \pm 0.038^{\mathrm{b}}$ & $1.019 \pm 0.042$ & $1.019 \pm 0.040$ \\
\hline GA-AC/GA-FL & $1.023 \pm 0.040$ & $1.030 \pm 0.043^{c}$ & $1.026 \pm 0.044$ & $1.040 \pm 0.040$ & $1.032 \pm 0.043^{b}$ & $1.030 \pm 0.040$ \\
\hline
\end{tabular}

Table 2. Results of fetal biometry and FAORs measured at 20-24 GW in the subjects subsequently diagnosed with NGT and GDM. GW gestational weeks, FAOR fetal abdominal overgrowth ratio, NGT normal glucose tolerance, GDM gestational diabetes mellitus, $B M I$ body mass index, GA-LMP gestational age by last menstruation period, $G A-A C$ estimated gestational age by abdominal circumference, $G A-B P D$ estimated gestational age by biparietal diameter, $G A-F L$ estimated gestational age by femur length, $E F W$ estimated fetal weight; GDM group 1 (age $<35$ years and $\left.\mathrm{BMI}<25 \mathrm{~kg} / \mathrm{m}^{2}\right)$; group $2\left(\right.$ age $<35$ years and $\left.\mathrm{BMI} \geq 25 \mathrm{~kg} / \mathrm{m}^{2}\right)$; group 3 (age $\geq 35$ years and $\mathrm{BMI}<25 \mathrm{~kg} / \mathrm{m}^{2}$ ); group 4 (age $\geq 35$ years and $\mathrm{BMI} \geq 25 \mathrm{~kg} / \mathrm{m}^{2}$ ). ${ }^{\mathrm{a}}$ Gestational age by LMP at 20-24 GW, ${ }^{b} \mathrm{p}<0.05$, compared with NGT, ${ }^{c} \mathrm{p}<0.001$, compared with NGT.

\begin{tabular}{|c|c|c|c|}
\hline & $\mathrm{NGT}^{\mathrm{a}}$ & $\mathbf{G D M}^{\mathrm{b}}$ & p-value \\
\hline \multicolumn{4}{|c|}{ GA-AC/GA-LMP } \\
\hline $20-21 \mathrm{GW}$ & $1.035 \pm 0.039$ & $1.042 \pm 0.036$ & 0.3688 \\
\hline $21-22 \mathrm{GW}$ & $1.030 \pm 0.036$ & $1.038 \pm 0.037$ & 0.0153 \\
\hline $22-23 \mathrm{GW}$ & $1.026 \pm 0.037$ & $1.034 \pm 0.039$ & 0.0093 \\
\hline $23-24 \mathrm{GW}$ & $1.018 \pm 0.037$ & $1.022 \pm 0.036$ & 0.4567 \\
\hline \multicolumn{4}{|c|}{ GA-AC/GA-BPD } \\
\hline $20-21 \mathrm{GW}$ & $1.017 \pm 0.043$ & $1.020 \pm 0.041$ & 0.7431 \\
\hline $21-22 \mathrm{GW}$ & $1.014 \pm 0.042$ & $1.021 \pm 0.045$ & 0.0717 \\
\hline $22-23 \mathrm{GW}$ & $1.012 \pm 0.043$ & $1.019 \pm 0.042$ & 0.0518 \\
\hline $23-24 \mathrm{GW}$ & $1.010 \pm 0.043$ & $1.017 \pm 0.042$ & 0.9459 \\
\hline \multicolumn{4}{|c|}{ GA-AC/GA-FL } \\
\hline $20-21 \mathrm{GW}$ & $1.029 \pm 0.039$ & $1.030 \pm 0.034$ & 0.8217 \\
\hline $21-22 \mathrm{GW}$ & $1.027 \pm 0.040$ & $1.035 \pm 0.042$ & 0.0252 \\
\hline $22-23 \mathrm{GW}$ & $1.022 \pm 0.040$ & $1.030 \pm 0.045$ & 0.0148 \\
\hline $23-24 \mathrm{GW}$ & $1.015 \pm 0.041$ & $1.023 \pm 0.044$ & 0.2025 \\
\hline \multicolumn{4}{|l|}{ EFW (g) } \\
\hline $20-21 \mathrm{GW}$ & $396.2 \pm 50.8$ & $406.3 \pm 62.5$ & 0.3138 \\
\hline $21-22 \mathrm{GW}$ & $460.3 \pm 55.5$ & $469.7 \pm 50.5$ & 0.0649 \\
\hline $22-23 \mathrm{GW}$ & $537.5 \pm 63.3$ & $544.9 \pm 60.6$ & 0.1643 \\
\hline $23-24 \mathrm{GW}$ & $620.2 \pm 70.5$ & $615.3 \pm 61.1$ & 0.6313 \\
\hline
\end{tabular}

Table 3. FAORs and EFW according to measured GW in the subjects subsequently diagnosed with NGT and GDM. FAOR fetal abdominal overgrowth ratio, EFW estimated fetal weight, NGT normal glucose tolerance, $G D M$ gestational diabetes mellitus, $G W$ gestational week, $G A-A C$ estimated gestational age by abdominal circumference, GA-LMP gestational age by last menstruation period, GA-BPD estimated gestational age

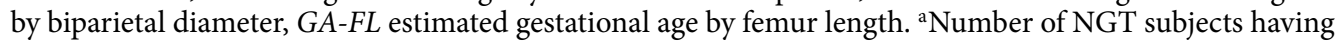
available data for FAORs and EFW at GW 20-21, 21-22, 22-23, and 23-24 were 486, 2344, 2688, and 951,

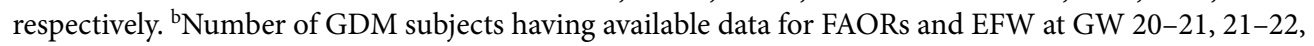
$22-23$, and $23-24$ were $28,124,148$, and 48 , respectively.

Correlation of FAORs measured at 20-24 GW with FAORs measured at the time of GDM diagnosis. All FAORs measured at 20-24 GW showed significant correlation with those subsequently measured at the time of GDM diagnosis (Supplementary Table S4). 


\begin{tabular}{|c|c|c|c|c|}
\hline & \multicolumn{2}{|l|}{ NGT $(n=6639)$} & \multicolumn{2}{|l|}{ GDM $(n=357)$} \\
\hline & FAO $(-)(n=5987)$ & FAO $(+)(n=652)$ & FAO $(-)(\mathbf{n}=307)$ & FAO $(+)(\mathbf{n}=50)$ \\
\hline \multicolumn{5}{|l|}{ Clinical and biochemical } \\
\hline Age (years) & $33.1 \pm 3.7$ & $34.0 \pm 3.9^{\mathrm{a}}$ & $35.1 \pm 3.9$ & $36.6 \pm 4.0^{\mathrm{a}}$ \\
\hline Pre-pregnancy BMI $\left(\mathrm{kg} / \mathrm{m}^{2}\right)$ & $20.6 \pm 2.5$ & $20.8 \pm 2.7^{\mathrm{a}}$ & $22.4 \pm 3.5$ & $22.0 \pm 2.9$ \\
\hline \multicolumn{5}{|l|}{ Weight gain $(\mathrm{kg})$} \\
\hline Pre-pregnancy-at diagnosis & $7.5 \pm 3.3$ & $8.0 \pm 3.1^{\mathrm{a}}$ & $7.8 \pm 3.5$ & $8.3 \pm 4.0$ \\
\hline HbAlc at diagnosis $(\%)^{b}$ & $5.0 \pm 0.3$ & $5.0 \pm 0.2$ & $5.3 \pm 0.5$ & $5.2 \pm 0.4$ \\
\hline $\mathrm{HbAlc}$ at diagnosis $(\mathrm{mmol} / \mathrm{mol})^{\mathrm{b}}$ & $31.3 \pm 3.5$ & $31.3 \pm 3.0$ & $34.4 \pm 6.0$ & $33.9 \pm 5.0$ \\
\hline FPG on $100-\mathrm{g}$ OGTT $(\mathrm{mg} / \mathrm{dL})^{\mathrm{b}}$ & $80.2 \pm 6.5$ & $80.3 \pm 5.7$ & $89.7 \pm 15.1$ & $87.7 \pm 10.3$ \\
\hline FPG on $100-\mathrm{g}$ OGTT $(\mathrm{mmol} / \mathrm{L})^{\mathrm{b}}$ & $4.5 \pm 0.4$ & $4.5 \pm 0.3$ & $5.0 \pm 0.8$ & $4.9 \pm 0.6$ \\
\hline HOMA-IR ${ }^{\mathrm{b}}$ & $1.6 \pm 0.9$ & $1.4 \pm 0.7$ & $2.3 \pm 1.2$ & $1.9 \pm 0.9^{\mathrm{a}}$ \\
\hline HOMA- $\beta^{b}$ & $172.1 \pm 92.3$ & $213.2 \pm 167.5$ & $157.2 \pm 89.1$ & $153.6 \pm 142.6$ \\
\hline FAO $(+)$ at diagnosis $(\%)$ & 5.6 & $20.4^{\mathrm{a}}$ & 11.1 & $34.0^{\mathrm{a}}$ \\
\hline \multicolumn{5}{|l|}{ Pregnancy outcomes } \\
\hline Primipara (\%) & 66.9 & $71.2^{\mathrm{a}}$ & 65.5 & 74.0 \\
\hline Male sex of infant (\%) & 50.3 & $73.6^{\mathrm{a}}$ & 52.4 & $80.0^{\mathrm{a}}$ \\
\hline LGA (\%) & 4.0 & $12.3^{\mathrm{a}}$ & 11.7 & 20.0 \\
\hline Macrosomia (\%) & 1.6 & $4.1^{\mathrm{a}}$ & 4.6 & 4.0 \\
\hline Cesarean delivery (\%) & 32.2 & $37.1^{\mathrm{a}}$ & 45.9 & 56.0 \\
\hline Primary cesarean delivery (\%) & 21.5 & $26.1^{\mathrm{a}}$ & 29.0 & $44^{\mathrm{a}}$ \\
\hline Male sex of infant (\%) & 50.3 & $73.6^{\mathrm{a}}$ & 52.4 & $80.0^{\mathrm{a}}$ \\
\hline LGA (\%) & 4.0 & $12.3^{\mathrm{a}}$ & 11.7 & 20.0 \\
\hline Macrosomia (\%) & 1.6 & $4.1^{\mathrm{a}}$ & 4.6 & 4.0 \\
\hline
\end{tabular}

Table 4. Clinical and biochemical characteristics and pregnancy outcomes by presence or absence of FAO at 20-24 GW in the subjects subsequently diagnosed with NGT and GDM. FAO fetal abdominal obesity, GW gestational weeks, NGT normal glucose tolerance, GDM gestational diabetes mellitus, $B M I$ body mass index, $H b A 1 c$ glycosylated hemoglobin, FPG fasting plasma glucose, OGTT oral glucose tolerance test, HOMA-IR homeostatic model assessment for insulin resistance, HOMA- $\beta$ homeostatic model assessment for insulin secretion, $L G A$ large for gestational age. ${ }^{\mathrm{a}} \mathrm{p}<0.05$ compared to FAO $(-)$, ${ }^{\mathrm{b}} \mathrm{Column}$ Ns for the variable are different from the Ns presented in the table.

\begin{tabular}{|c|c|c|c|}
\hline & \multicolumn{3}{|l|}{ Odds ratio $(95 \% \mathrm{CI})$} \\
\hline & FAO at diagnosis (+) & LGA at birth & Macrosomia \\
\hline \multicolumn{4}{|l|}{ NGT } \\
\hline $\mathrm{FAO}^{\mathrm{a}}$ at $20-24 \mathrm{GW}(-)$ & 1 (ref.) & 1 (ref.) & 1 (ref.) \\
\hline FAO at $20-24 \mathrm{GW}(+)$ & $4.56^{\mathrm{b}}(3.63,5.74)$ & $3.50^{\mathrm{b}}(2.68,4.59)$ & $2.68^{\mathrm{b}}(1.73,4.14)$ \\
\hline \multicolumn{4}{|l|}{ GDM } \\
\hline FAO at $20-24 \mathrm{GW}(-)$ & $2.03^{\mathrm{b}}(1.39,2.97)$ & $3.10^{\mathrm{b}}(2.14,4.51)$ & $2.96^{\mathrm{b}}(1.67,5.26)$ \\
\hline FAO at $20-24 \mathrm{GW}(+)$ & $10.15^{\mathrm{b}}(5.27,19.57)$ & $5.57^{\mathrm{b}}(2.75,11.29)$ & $2.58(0.62,10.79)$ \\
\hline
\end{tabular}

Table 5. Odds ratios of FAO at the time of diagnosis of GDM, LGA at birth, and macrosomia by NGT and GDM subjects and by presence or absence of FAO at 20-24 GW. FAO fetal abdominal obesity, GDM gestational diabetes mellitus, $L G A$ large for gestational age, $G W$ gestational weeks, NGT normal glucose tolerance. ${ }^{a}$ Fetal abdominal obesity defined as fetal abdominal overgrowth ratio $\geq 90$ th, ${ }^{b} \mathrm{p}<0.05$ compared with NGT FAO (-).

\section{Discussion}

The association between GDM and increased fetal adiposity has been known to be limited to late pregnancy ${ }^{19-22}$ and appropriate management of GDM initiated even at $\geq 30 \mathrm{GW}^{23}$ was reported to reduce the risks of GDM complications such as fetal overgrowth, shoulder dystocia and cesarean delivery ${ }^{4,5}$. So, the universal GDM screening of pregnant women at $24-28 \mathrm{GW}$ is now recommended by many professional societies ${ }^{24-27}$. However, childhood obesity or metabolic dysfunction in the offspring of mild GDM subjects was not reduced by treatment of GDM ${ }^{6,7}$. This suggests that current management to reduce LGA and macrosomia is not sufficient for the prevention of long-term complication of GDM in the offspring.

FAO might serve as an early indicator of GDM and GDM complication. Fetal abdominal overgrowth was observed earlier than usual time of GDM diagnosis ${ }^{10}$ and even in the fetus with appropriate weight for gestational age $\mathrm{e}^{28}$. Moreover, FAO might also be a significant risk factor for early childhood and later in life obesity ${ }^{28,29}$. 
According to our previous studies, GDM diagnosed at 24-28 GW has already affected FAO in the older ( $\geq 35$ years) and/or obese $\left(\mathrm{BMI} \geq 25 \mathrm{~kg} / \mathrm{m}^{2}\right.$ ) women but not in the young and non-obese women ${ }^{17}$ and FAO persisted until delivery despite treatment of $\mathrm{GDM}^{18}$. The prevalence of near-term FAO leading to significantly higher infant birth weight and cesarean section rate were threefold higher in GDM with FAO than without FAO at $24-28 \mathrm{GW}^{18}$.

In the present study, FAO was already observed at 20-24 GW, well predating the time of GDM diagnosis at 24-28 GW, in the older and/or obese but not in the young and non-obese women. Furthermore, the odds ratios for exhibiting FAO at diagnosis of GDM and LGA at birth were tenfold and fivefold higher, respectively, in the GDM subjects with FAO than NGT subjects without FAO at 20-24 GW.

Sovio et al. reported that fetal abdominal overgrowth was not observed at $20 \mathrm{GW}$ in the women who subsequently diagnosed with GDM. However, obese women already had an increased risk of fetal abdominal overgrowth in fetal biometry at that time and were at higher risk if later diagnosed with $\mathrm{GDM}^{8}$.

Overall, these findings suggest that while the current universal GDM screening and treatment initiated at 24-28 GW might be appropriate for the young and non-obese women, much earlier GDM diagnosis before the onset of FAO and careful management would be necessary to prevent the development of FAO in the high risk older and/or obese women.

Determining the optimal time frame for GDM screening and initiation of treatment before the onset of FAO might be a clinically important issue to improve the maternal and newborn outcomes. Several studies reported that earlier recognition of women at risk for the development of GDM and other adverse pregnancy outcomes might benefit from earlier detection and intervention ${ }^{15,30,31}$. However, in a study that GDM subjects were stratified by GA at initiation of treatment from 24 to $30 \mathrm{GW}$, earlier initiation of GDM treatment was not associated with favorable pregnancy outcomes ${ }^{23}$. According to Sweeting et al., pregnancy outcomes of women who was diagnosed with GDM before $12 \mathrm{GW}$ and had higher HbAlc at diagnosis was poor and similar to those of preexisting diabetes despite early testing and best practice treatment. But GDM subjects diagnosed at 12-23 GW and after $24 \mathrm{GW}$ showed similar frequency of LGA at birth and macrosomia ${ }^{32}$. Considering that FAO was already present at 20-24 GW and frequency of LGA is significantly higher in the GDM subjects with FAO than those without FAO in our study, the pregnancy outcome of the earlier diagnosed GDM subjects at 12-23 GW can be interpreted as favorable results of early diagnosis, while initiation of treatment later than $24 \mathrm{GW}$ was thought to be too late to expect favorable outcome. For the GDM subjects diagnosed before $12 \mathrm{GW}$, it is thought that pre-pregnancy screening for type 2 diabetes mellitus should have been performed.

According to meta-analysis by Immanuel et al. ${ }^{33}$, relative risk for perinatal mortality, neonatal hypoglycemia, and insulin use in early-onset ( $<24 \mathrm{GW}) \mathrm{GDM}$ women were $3.58,1.61$, and 1.71 , respectively compared to lateonset (24-28 GW) GDM women. In the pilot randomized controlled trial (RCT) with pregnant women who had GDM risk factors and took an OGTT earlier than $20 \mathrm{GW}$, pregnancy outcomes were compared between women receiving immediate or deferred treatment after booking ${ }^{34}$. Early treatment of booking GDM subjects reduced frequency of neonatal macrosomia instead of increasing the frequency of SGA infants. Therefore, a full multicenter RCT for 4000 pregnant women $(<20 \mathrm{GW})$ at risk of overt diabetes in pregnancy is underway under the name of TOBOGM (treatment of booking gestational diabetes mellitus) study ${ }^{35}$.

In our study, FAOR of GDM subject began to deviate significantly from those of NGT subjects at $21 \mathrm{GW}$ and odds ratio for FAO in GDM subjects was significantly increased at $21 \mathrm{GW}$. In concordance with our data, Sovio et al. reported the development of FAO between 20 and $28 \mathrm{GW}$ in the GDM subjects ${ }^{8}$. Also, fetus of GDM subjects were reported to begin to have higher EFW than NGT fetus at $20 \mathrm{GW}$, the difference reached statistical significance at $28 \mathrm{GW}$, and showed abdominal overgrowth compared to head growth at $29 \mathrm{GW}^{9}$. But FAO was observed even at $20 \mathrm{GW}$, far predating the biochemical diagnosis of GDM, in the South African study of Venkataraman et al. ${ }^{10}$.

Collectively, these findings also suggest that much earlier diagnosis of GDM well before 20 GW would be necessary to prevent the development of FAO and subsequent progress to LGA infants and childhood obesity in the high risk older and/or obese women.

It is well known that both the fetal glucose homeostasis and the trajectory of intrauterine growth are consequences of intricate connections between the fetal endocrine system and placental function, which is affected by uterine blood flow and maternal health and nutrition, especially in elderly primiparas ${ }^{36}$. Nevertheless, maternal hyperglycemia was the strongest predictor of FAO in GDM subjects ${ }^{12,28,37}$ because fetal energy requirement for metabolism and growth is met mainly by glucose from mother ${ }^{38}$. In the subgroup analysis of this study, GDM subjects with FAO at 20-24 GW was not more obese but older than the subjects without FAO at 20-24 GW. In addition, while HOMA-IR of GDM with FAO at 20-24 GW was not significantly higher than those of NGT with FAO, HOMA- $\beta$ was lower than NGT without significance. This finding suggests that maternal metabolic abnormality of GDM mother with FAO at 20-24 GW is primarily reduced insulin secretion due to maternal old age, rather than markedly increased insulin resistance. As a result, maternal hyperglycemia occurred in early pregnancy and fetal hyperinsulinemia with FAO was developed subsequently at 20-24 GW in the high risk older and/or obese GDM women. Furthermore, it is thought that hyperinsulinemic fetuses may have lowered maternal glucose levels through exaggerated glucose steal ${ }^{39}$.

Our findings that FAO leading to adverse pregnancy outcome is associated with decreased insulin secretion rather than insulin resistance is different from the European data that GDM women with high insulin resistance showed poor pregnancy outcomes ${ }^{40}$. Recently, metabolic phenotypes of early GDM based on insulin resistance and secretion and their association with adverse pregnancy outcomes was reported ${ }^{41}$. Compared with NGT women, GDM women with high insulin resistance had a greater risk of having LGA and cesarean delivery while GDM women with lower insulin secretion or both abnormalities had comparable pregnancy outcome with those in NGT women. These findings are explained by ethnic difference that Asians have higher insulin sensitivity and 
lower insulin response than Caucasians ${ }^{42}$. In addition, decreased insulin secretion appears to be a major factor in the development of type 2 diabetes in Asian population ${ }^{43}$.

It is of note that fetal fat deposition begins at $14 \mathrm{GW}$ coinciding with the onset time of early fetal hyperinsulinemia ${ }^{13}$. In the present study, FAO detected at 20-24 GW increased the odds for exhibiting FAO at GDM diagnosis 5 folds in GDM subjects ( 10.15 vs. 2.03, Table 5), but odds ratio for LGA at birth and macrosomia were elevated less than 2 folds with the management of GDM in comparison with GDM subjects without FAO at 20-24 GW. In concordance with our data, there is a report that while birth weight was normalized with tight glycemic control in later pregnancy, but already developed fetal hyperinsulinemia resulting in persistent FAO was difficult to normalize ${ }^{28}$. Therefore, to further improve pregnancy outcomes related to fetal hyperinsulinemia and the ensuing FAO in the high risk older and/or obese GDM as well as in pre-existing diabetes, pre-pregnancy planning and better means to optimize metabolic control early in pregnancy would be necessary. However, in young and non-obese women who are not at high risk for fetal overgrowth and women without family history of diabetes and history of previous GDM and delivery of macrosomic baby, screening for GDM and initiation of medical nutrition therapy at 24-28 GW might be effective to prevent adverse birth outcomes.

Normalization of fetal hyperinsulinemia which is related with maternal hyperglycemia is most important for the prevention of fetal abdominal overgrowth. Initiation of insulin treatment in GDM subjects according to amniotic fluid insulin concentration markedly reduced the rate of elevated cord blood c-peptide levels in neonates ${ }^{44}$. Measurement of insulin in amniotic fluid or cord blood is not easy for detection of fetal hyperinsulinemia. If the association between FAORs and insulin or c-peptide levels in cord blood or amniotic fluid is defined through investigation, FAORs which we measured could be used as a surrogate marker for fetal hyperinsulinemia.

The limitations of the present study include the single center, retrospective, and uncontrolled observational study design. So, number of subjects scanned by ultrasound in each gestational week between 20 and 24 were not same in the study which we investigate when the FAORs of GDM subjects were significantly different from those of NGT subjects. Inter-observer variability on the assessment via the ultrasonography was not evaluated because of the retrospective nature of this study. But there were no differences in the ultrasound scanners used, and all pregnant women scanned were randomly assigned to one of the three sonographers. The strengths of this study include a relatively large sample size with the same ethnicity and clinical management of all subjects according to the same protocol throughout the study period.

In summary, FAO was already present at 20-24 GW in the high risk older and/or obese GDM but not in the young and non-obese GDM subjects. Furthermore, FAO at 20-24 GW in GDM subjects was associated with higher odds ratios for FAO at the time of GDM diagnosis and LGA at birth, 10.15 and 5.57, respectively. These findings suggest that much earlier diagnosis and active interventions of GDM before or early in pregnancy might be necessary to prevent FAO ultimately resulting in metabolic abnormality even up to childhood and adolescence, especially in the high risk older and/or obese GDM women.

\section{Methods}

Subjects and data collection. We retrospectively reviewed the medical records of 7820 singleton pregnant women who were followed up at the outpatient clinic of CHA Gangnam Medical Center from January 1, 2012, to April 31, 2015. Among them, 6996 women who had fetal biometry data measured 20-24 GW and delivered at CHA Gangnam Medical Center were included in this study. The data on maternal height, body weight in pre-pregnancy and at the 50-g GCT, biochemical test, and fetal biometry were obtained from the medical records. All subjects included in this study were Asian. This study did not examine socioeconomic status. The data collection was approved by the Institutional Review Board (IRB) of CHA Gangnam Medical Center with a waiver of informed consent for the retrospective chart review (CHA Gangnam Medical Center-IRB No. GCI-1810). All experiments were performed in accordance with relevant guidelines and regulations.

Diagnosis of GDM. As described previously ${ }^{17}$, all pregnant women were universally recommended to undergo screening with a 50-g GCT irrespective of fasting at 24-28 GW and subsequent a 3-h 100-g OGTT with measurements of fasting insulin and HbA1c after more than an 8-h fasting if the 50-g GCT result was $\geq 140 \mathrm{mg} /$ dL. The diagnosis of GDM and NGT depended on the Carpenter-Coustan criteria. Only one abnormal value on 100-g OGTT according to the Carpenter-Coustan criteria was diagnosed as impaired glucose tolerance (IGT). Among the total of 7569 subjects screened with a 50 -g GCT, 1186 women with glucose $\geq 140 \mathrm{mg} / \mathrm{dL}$ on the 50 -g GCT underwent a 100-g OGTT whereas 47 did not. Of these, 552 had NGT, 250 had impaired glucose tolerance, and 384 had GDM. From the 6888 NGT and 384 GDM subjects, 167 and 6 subjects delivered at other hospital respectively, and 82 and 21 subjects had no fetal biometry data measured at 20-24 GW, respectively. As a result, 6639 NGT and 357 GDM subjects were included in the study (Fig. 1). A total of 357 GDM subjects were divided into four study groups according to maternal age and pre-pregnancy BMI-group 1 (age $<35$ years and $\mathrm{BMI}<25 \mathrm{~kg} / \mathrm{m}^{2}[\mathrm{n}=135]$ ), group 2 (age $<35$ years and BMI $\geq 25 \mathrm{~kg} / \mathrm{m}^{2}[\mathrm{n}=20]$ ), group 3 (age $\geq 35$ years and $\left.\mathrm{BMI}<25 \mathrm{~kg} / \mathrm{m}^{2}[\mathrm{n}=154]\right)$, and group 4 (age $\geq 35$ years and $\left.\mathrm{BMI} \geq 25 \mathrm{~kg} / \mathrm{m}^{2}[\mathrm{n}=48]\right)$.

Fetal biometry. We collected fetal biometry data measured at 20-24 GW $(n=6996)$ as a routine anomaly scan and simultaneously with the 50-g GCT $(\mathrm{n}=5388)$ at 24-28 GW. Among them, 5075 subjects had fetal biometry data measured at both times. Gestational dating was confirmed in $87 \%$ of these women by fetal ultrasonography performed prior to $14 \mathrm{GW}$. BPD, FL, and AC were measured three times via ultrasonography (GE Healthcare, USA) by one of the experienced 3 sonographers, and the mean values were converted to each estimated GA (i.e., GA-BPD, GA-FL, and GA-AC) according to the Japanese fetal growth chart ${ }^{45,46}$ (Fig. S1). But interobserver variability was not evaluated due to the retrospective nature of this study. We calculated 2 sets of FAORs as GA-AC/GA-LMP (actual GA measured by the last menstruation period) to correct for the variations 


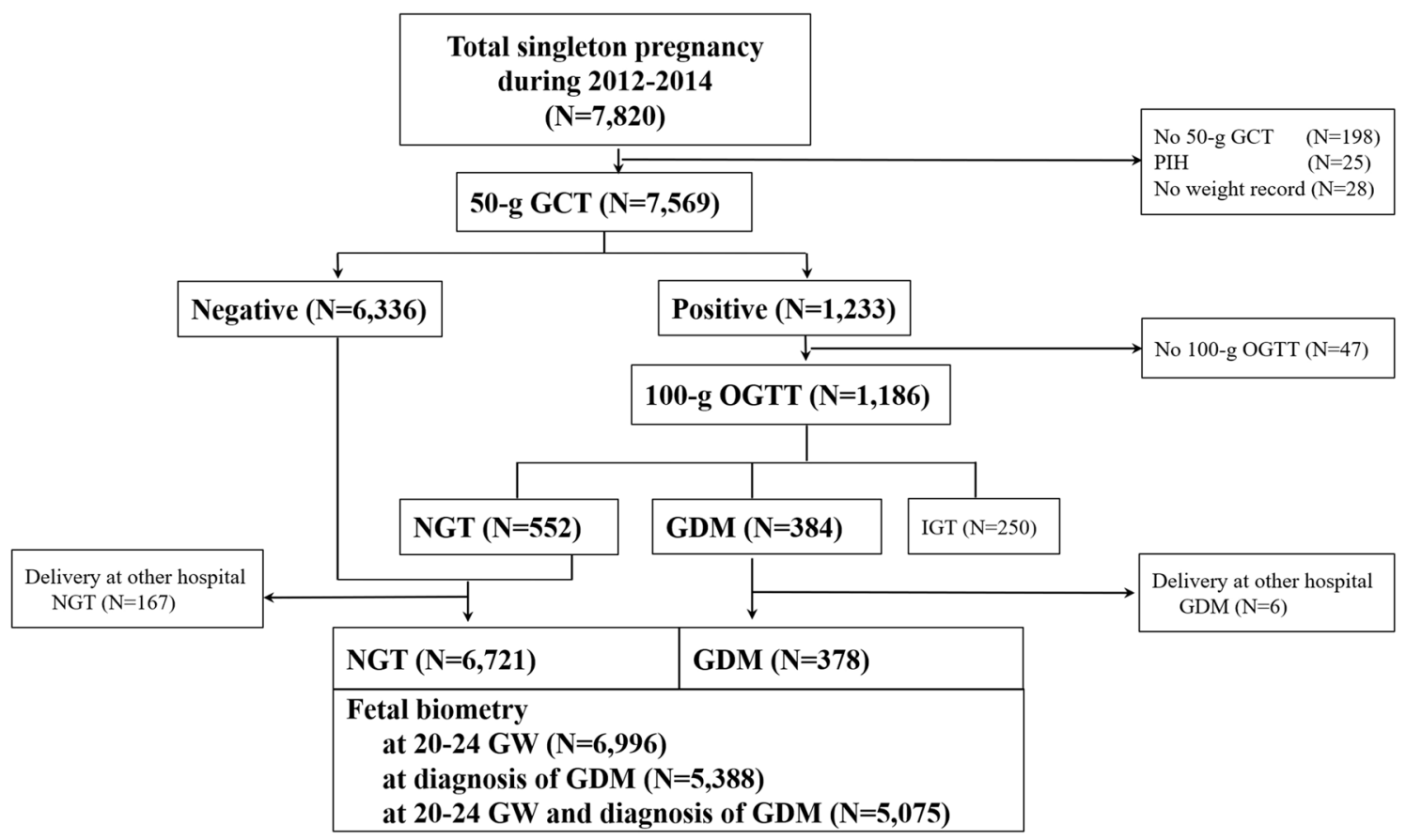

Figure 1. Study flow gram. GCT glucose challenge test, $P I H$ pregnancy induced hypertension, OGTT oral glucose tolerance test, NGT normal glucose tolerance, GDM gestational diabetes mellitus, IGT impaired glucose tolerance, $G W$ gestational week.

in the ultrasound scan timing, and GA-AC/GA-BPD or GA-AC/GA-FL to detect overgrowth of the abdomen relative to the head and femur growth, respectively. The presence of FAO was defined as FAORs $\geq 90$ th percentile of the total subjects with fetal biometry (GA-AC/GA-LMP $\geq 1.076$, GA-AC/GA-BPD $\geq 1.070$, GA-AC/ GA-FL $\geq 1.077$ at $20-24$ GW; GA-AC/GA-LMP $\geq 1.080$, GA-AC/GA-BPD $\geq 1.071$, GA-AC/GA-FL $\geq 1.069$ at the time of 50-g GCT). Although bigger AC also could be due to enlarged liver or other causes, AC has been used as a proxy of increased fetal fat accretion. So, we defined fetal abdominal obesity as FAOR $\geq 90$ th percentile and use the term. The estimated fetal weight was calculated using the Shinozuka formula ${ }^{47}$. We defined LGA at birth as $\geq 90$ th percentile of gestational age matched birth weight according to the report of Committee of the Korean Society of Neonatology by Lee et al. ${ }^{48}$. Macrosomia was defined as infant birth weight $\geq 4 \mathrm{~kg}$.

A diagnosis of GDM was made shortly after screening, usually within one week. Therefore, we use the phrase "at the time of GDM diagnosis" to describe the fetal biometry performed on the same day of the 50-g GCT. We also abbreviate this phrase to "at diagnosis."

Biochemical analysis. Plasma glucose was measured using the hexokinase method (Quailigentglu, Sekisui, Japan), and HbAlc was measured via high-performance liquid chromatography (G8 Elution Buffer, Tosoh, Tokyo, Japan). The plasma insulin concentration was determined via electrochemiluminescence immunoassay (ElecsysInsulin, Roche Diagnostics GmbH, Mannheim, Germany). Insulin resistance (homeostatic model assessment for insulin resistance [HOMA-IR]) and secretion (HOMA- $\beta$ ) were calculated by homeostasis model assessment $^{49}$.

\section{Statistical analyses}

Clinical and biochemical characteristics were reported as mean with standard deviation and proportion. Pregnancy outcomes such as primipara, cesarean delivery, primary cesarean delivery, LGA, and macrosomia were reported as proportions. Other pregnancy outcomes such as infant birth weight (g) and GA at delivery (weeks) were summarized as mean and standard deviation. Univariate associations of the characteristics or outcomes between NGT and total GDM or each of subgroups of GDM according to maternal age and pre-pregnancy BMI were investigated using two sample $t$ test and test of two proportions. Pairwise associations among subgroups of GDM were investigated using post hoc analysis following one-way analysis of variance (ANOVA) using Tukey's method for continuous variables. Where the assumptions of one-way ANOVA were not met, Kruskal-Wallis test followed by Dunn's test as a post hoc analysis was conducted. For categorical variables, pairwise associations among GDM subgroups were investigated using test of two proportions for all possible pairs of subgroups.

Fetal biometry data and FAORs were described as mean and standard deviation and two sample $t$ test was used for investigating univariate associations between NGT and total GDM or each subgroup of GDM. Assumptions of two sample $t$ test were checked using Shapiro-Wilk test and Bartlett's test for the fetal biometry measures and FAORs.

Further, FAORs and EFW were summarized as mean and standard deviation and compared between NGT and GDM subjects according to each week of 20-24 GW using two sample $t$ test. 
For the subgroup analysis, within NGT and GDM, subjects with FAO at 20-24 GW and those without were compared for clinical and biochemical characteristics and pregnancy outcomes. Continuous variables were tested using two sample $t$ test and categorical variables were compared using test of two proportions.

Odds ratio of having FAO at the time of GDM diagnosis, being LGA at birth, and macrosomia were estimated using logistic regression analysis models by NGT and GDM subject and by having FAO at 20-24 GW or not. NGT subjects with FAO at 20-24 GW and GDM subjects with and without FAO at 20-24 GW were compared to NGT subjects without FAO at 20-24 GW.

Correlations were assessed by Pearson's correlation coefficient. All analyses were conducted using STATA version 15.1 (StataCorp LP, College Station, TX, USA). The level of significance for the analyses was 0.05.

Subgroup analysis of GDM subjects according to maternal age and pre-pregnancy BMI. A total GDM subjects were divided into four study groups according to maternal age (35 years) and pre-pregnancy BMI $\left(25 \mathrm{~kg} / \mathrm{m}^{2}\right)$. We compared the clinical and biochemical profiles and the fetal biometry data between GDM and NGT subjects. The GDM subgroup data were compared with each other and, also with those of the NGT subjects.

Logistic regression models were used to estimate the odds of FAO at 20-24 GW in total GDM or subgroup of GDM versus NGT subjects. Specific to GDM subgroup 2, an exact logistic regression model rather than a regular logistic regression model was implemented to reduce potential bias resulting from the lower number of participants in the group $(\mathrm{n}=20)$.

Subgroup analysis in the NGT and GDM subjects according to presence or absence of FAO at 20-24 GW. A total of 6996 subjects were divided into the following four study groups according to the presence or absence of FAO at 20-24 weeks of gestation: NGT without FAO ( $n=5988)$, NGT with FAO $(n=651)$, GDM without FAO $(n=307)$, and GDM with FAO $(n=50)$. We compared the clinical and biochemical parameters of mothers and pregnancy outcomes between the study groups.

We also investigated odd ratios of exhibiting FAO at the time of GDM diagnosis, being LGA at birth, and macrosomia in the NGT subjects with FAO and GDM subjects with and without FAO at 20-24 GW relative to the NGT subjects without FAO at 20-24 GW.

Subgroup analysis in the NGT and GDM subjects according to the GW at fetal biometry performed. Subjects were grouped according to GW at which fetal biometry was performed to investigate when GDM subjects begin to show higher FAORs than NGT subjects. The mean FAOR for each GW was compared between GDM and NGT subjects. Further, the odd ratios for FAO in GDM subjects were estimated in comparison with NGT subjects.

\section{Data availability}

Further information about data and resources will be provided upon request to the corresponding author.

Received: 20 May 2021; Accepted: 26 November 2021

Published online: 10 December 2021

\section{References}

1. Viner, R., White, B. \& Christie, D. Type 2 diabetes in adolescents: A severe phenotype posing major clinical challenges and public health burden. Lancet 389, 2252-2260. https://doi.org/10.1016/S0140-6736(17)31371-5 (2017).

2. NCD Risk Factor Collaboration. Worldwide trends in body-mass index, underweight, overweight, and obesity from 1975 to 2016 : A pooled analysis of 2416 population-based measurement studies in 128.9 million children, adolescents, and adults. Lancet $\mathbf{3 9 0}$, 2627-2642. https://doi.org/10.1016/S0140-6736(17)32129-3 (2017).

3. Ogden, C. L. et al. Trends in obesity prevalence among children and adolescents in the United States, 1988-1994 through 20132014. JAMA 315, 2292-2299. https://doi.org/10.1001/jama.2016.6361 (2016).

4. Crowther, C. A. et al. Effect of treatment of gestational diabetes mellitus on pregnancy outcomes. N. Engl. J. Med. 352, 2477-2486. https://doi.org/10.1056/NEJMoa042973 (2005).

5. Landon, M. B. et al. A multicenter, randomized trial of treatment for mild gestational diabetes. N. Engl. J. Med. 361, 1339-1348. https://doi.org/10.1056/NEJMoa0902430 (2009).

6. Gillman, M. W. et al. Effect of treatment of gestational diabetes mellitus on obesity in the next generation. Diabetes Care 33, 964-968. https://doi.org/10.2337/dc09-1810 (2010).

7. Landon, M. B. et al. Mild gestational diabetes mellitus and long-term child health. Diabetes Care 38, 445-452. https://doi.org/10. 2337/dc14-2159 (2015).

8. Sovio, U., Murphy, H. R. \& Smith, G. C. Accelerated fetal growth prior to diagnosis of gestational diabetes mellitus: A prospective cohort study of nulliparous women. Diabetes Care 39, 982-987. https://doi.org/10.2337/dc16-0160 (2016).

9. Li, M. et al. Glycaemic status during pregnancy and longitudinal measures of fetal growth in a multi-racial US population: A prospective cohort study. Lancet Diabetes Endocrinol. 8, 292-300. https://doi.org/10.1016/S2213-8587(20)30024-3 (2020).

10. Venkataraman, H. et al. Increased fetal adiposity prior to diagnosis of gestational diabetes in South Asians: More evidence for the "thin-fat" baby. Diabetologia 60, 399-405. https://doi.org/10.1007/s00125-016-4166-2 (2017).

11. Pedersen, J. \& Osler, M. Hyperglycemia as the cause of characteristic features of the foetus and newborn of diabetic mothers. Dan. Med. Bull. 8, 78-83 (1961).

12. HAPO Study Cooperative Research Group. Hyperglycemia and adverse pregnancy outcome (HAPO) study: Associations with neonatal anthropometrics. Diabetes 58, 453-459. https://doi.org/10.2337/db08-1112 (2009).

13. Poissonnet, C. M., Burdi, A. R. \& Bookstein, F. L. Growth and development of human adipose tissue during early gestation. Early Hum. Dev. 8, 1-11. https://doi.org/10.1016/0378-3782(83)90028-2 (1983).

14. Chiefari, E., Quaresima, P., Visconti, F., Mirabelli, M. \& Brunetti, A. Gestational diabetes and fetal overgrowth: Time to rethink screening guidelines. Lancet Diabetes Endocrinol. 8, 561-562. https://doi.org/10.1016/S2213-8587(20)30189-3 (2020). 
15. Italian Ministry of Health. Italian Ministry of Health guidelines, Italian Ministry of Health: Linee guida gravidanza fisiologica aggiornamento 2011: Sistema nazionale per le linee guida dell'Istituto Superiore di Sanità. https://www.salute.gov.it/imgs/C_17_ pubblicazioni_1436_allegato.pdf (2011).

16. Quaresima, P. et al. Appropriate timing of gestational diabetes mellitus diagnosis in medium- and low-risk women: Effectiveness of the Italian NHS recommendations in preventing fetal macrosomia. J. Diabetes Res. 2020, 5393952. https://doi.org/10.1155/ 2020/5393952 (2020).

17. Kim, W., Park, S. K. \& Kim, Y. L. Gestational diabetes mellitus diagnosed at 24 to 28 weeks of gestation in older and obese women: Is it too late?. PLoS One 14, e0225955. https://doi.org/10.1371/journal.pone.0225955 (2019).

18. Kim, W., Park, S. K. \& Kim, Y. L. Fetal abdominal obesity detected at 24 to 28 weeks of gestation persists until delivery despite management of gestational diabetes mellitus. Diabetes Metab. J. https://doi.org/10.4093/dmj.2020.0078 (2021).

19. Tantanasis, T. et al. Sonographic assessment of fetal subcutaneous fat tissue thickness as an indicator of gestational diabetes. Eur. J. Obstet. Gynecol. Reprod. Biol. 152, 157-162. https://doi.org/10.1016/j.ejogrb.2010.05.035 (2010).

20. de Santis, M. S. et al. Growth of fetal lean mass and fetal fat mass in gestational diabetes. Ultrasound Obstet. Gynecol. 36, 328-337. https://doi.org/10.1002/uog.7575 (2010).

21. Larciprete, G. et al. Fetal subcutaneous tissue thickness (SCTT) in healthy and gestational diabetic pregnancies. Ultrasound Obstet. Gynecol. 22, 591-597. https://doi.org/10.1002/uog.926 (2003).

22. Aksoy, H. et al. Fetal anterior abdominal wall thickness may be an early ultrasonographic sign of gestational diabetes mellitus. J. Matern. Fetal Neonatal Med. 29, 2028-2032. https://doi.org/10.3109/14767058.2015.1072164 (2016).

23. Palatnik, A. et al. Timing of treatment initiation for mild gestational diabetes mellitus and perinatal outcomes. Am. J. Obstet. Gynecol. 213(560), e561-e568. https://doi.org/10.1016/j.ajog.2015.06.022 (2015).

24. American Diabetes Association. 2. Classification and diagnosis of diabetes: Standards of medical care in diabetes-2019. Diabetes Care 42, S13-S28. https://doi.org/10.2337/dc19-S002 (2019).

25. Gestational Diabetes Mellitus. Committee on Practice, B.-O. ACOG Practice Bulletin No. 190. Obstet. Gynecol. 131, e49-e64. https://doi.org/10.1097/AOG.0000000000002501 (2018).

26. Moyer, V. A., U.S. Preventive Services Task Force. Screening for gestational diabetes mellitus: U.S. Preventive Services Task Force recommendation statement. Ann. Intern. Med. 160, 414-420. https://doi.org/10.7326/M13-2905 (2014).

27. Blumer, I. et al. Diabetes and pregnancy: An endocrine society clinical practice guideline. J. Clin. Endocrinol. Metab. 98, 4227-4249. https://doi.org/10.1210/jc.2013-2465 (2013).

28. Catalano, P. M., Thomas, A., Huston-Presley, L. \& Amini, S. B. Increased fetal adiposity: A very sensitive marker of abnormal in utero development. Am. J. Obstet. Gynecol. 189, 1698-1704. https://doi.org/10.1016/s0002-9378(03)00828-7 (2003).

29. Rogers, I., EURO-BLCS Study Group. The influence of birthweight and intrauterine environment on adiposity and fat distribution in later life. Int. J. Obes. Relat. Metab. Disord. 27, 755-777. https://doi.org/10.1038/sj.ijo.0802316 (2003).

30. Bartha, J. L., Martinez-Del-Fresno, P. \& Comino-Delgado, R. Early diagnosis of gestational diabetes mellitus and prevention of diabetes-related complications. Eur. J. Obstet. Gynecol. Reprod. Biol. 109, 41-44. https://doi.org/10.1016/s0301-2115(02)00480-3 (2003).

31. Seshiah, V. et al. Detection and care of women with gestational diabetes mellitus from early weeks of pregnancy results in birth weight of newborn babies appropriate for gestational age. Diabetes Res. Clin. Pract. 80, 199-202. https://doi.org/10.1016/j.diabr es.2007.12.008 (2008).

32. Sweeting, A. N. et al. Gestational diabetes mellitus in early pregnancy: Evidence for poor pregnancy outcomes despite treatment. Diabetes Care 39, 75-81. https://doi.org/10.2337/dc15-0433 (2016).

33. Immanuel, J. \& Simmons, D. Screening and treatment for early-onset gestational diabetes mellitus: A systematic review and metaanalysis. Curr. Diabetes Rep. 17, 115. https://doi.org/10.1007/s11892-017-0943-7 (2017).

34. Simmons, D. et al. The treatment of booking gestational diabetes mellitus (TOBOGM) pilot randomised controlled trial. BMC Pregnancy Childbirth 18, 151. https://doi.org/10.1186/s12884-018-1809-y (2018).

35. Simmons, D. et al. Hyperglycaemia in early pregnancy: The Treatment of Booking Gestational diabetes Mellitus (TOBOGM) study. A randomised controlled trial. Med. J. Aust. 209, 405-406. https://doi.org/10.5694/mja17.01129 (2018).

36. Mirabelli, M. et al. Gestational diabetes: Implications for fetal growth, intervention timing, and treatment options. Curr. Opin. Pharmacol. 60, 1-10. https://doi.org/10.1016/j.coph.2021.06.003 (2021).

37. Lowe, L. P. et al. Hyperglycemia and Adverse Pregnancy Outcome (HAPO) Study: Associations of maternal A1C and glucose with pregnancy outcomes. Diabetes Care 35, 574-580. https://doi.org/10.2337/dc11-1687 (2012).

38. Beardsall, K. \& Ogilvy-Stuart, A. L. Developmental physiology of carbohydrate metabolism and the pancreas. In Maternal-Fetal and Neonatal Endocrinology (eds Kovacs, C. S. \& Deal, C. L.) 587-597 (Elsevier, 2019).

39. Desoye, G. \& Nolan, C. J. The fetal glucose steal: An underappreciated phenomenon in diabetic pregnancy. Diabetologia 59, 1089-1094. https://doi.org/10.1007/s00125-016-3931-6 (2016).

40. Benhalima, K. et al. Characteristics and pregnancy outcomes across gestational diabetes mellitus subtypes based on insulin resistance. Diabetologia 62, 2118-2128. https://doi.org/10.1007/s00125-019-4961-7 (2019).

41. Immanuel, J. et al. Metabolic phenotypes of early gestational diabetes mellitus and their association with adverse pregnancy outcomes. Diabetes Med. 38, e14413. https://doi.org/10.1111/dme.14413 (2021).

42. Kodama, K. et al. Ethnic differences in the relationship between insulin sensitivity and insulin response: A systematic review and meta-analysis. Diabetes Care 36, 1789-1796. https://doi.org/10.2337/dc12-1235 (2013).

43. Yang, S. J. et al. Insulin secretion and insulin resistance in Korean women with gestational diabetes mellitus and impaired glucose tolerance. Korean J. Intern. Med. 28, 306-313. https://doi.org/10.3904/kjim.2013.28.3.306 (2013).

44. Weiss, P. A., Hofmann, H. M., Kainer, F. \& Haas, J. G. Fetal outcome in gestational diabetes with elevated amniotic fluid insulin levels. Dietary versus insulin treatment. Diabetes Res. Clin. Pract. 5, 1-7. https://doi.org/10.1016/s0168-8227(88)80071-8 (1988).

45. Shinozuka, N., Masuda, H., Kagawa, H. \& Taketani, Y. Standard values of ultrasonographic fetal biometry. Jpn. J. Med. Ultrason. 23, 877-888 (1996).

46. Shinozuka, N. et al. Okai T ellipse tracing fetal growth assessment using abdominal circumference. J. Med. Ultrasound 8, 87-94 (2000).

47. Shinozuka, N. et al. Formulas for fetal weight estimation by ultrasound measurements based on neonatal specific gravities and volumes. Am. J. Obstet. Gynecol. 157, 1140-1145. https://doi.org/10.1016/s0002-9378(87)80278-8 (1987).

48. Lee, J. J. et al. The study of growth measurements at different gestational ages of Korean newborn the survey and statistics. J. Korean Soc. Neonatol. 13, 47-57 (2006).

49. Matthews, D. R. et al. Homeostasis model assessment: Insulin resistance and beta-cell function from fasting plasma glucose and insulin concentrations in man. Diabetologia 28, 412-419. https://doi.org/10.1007/bf00280883 (1985).

\section{Acknowledgements}

The authors would like to express sincere gratitude to Prof. WS Park of Samsung Medical Center, Sungkyunkwan University, for his advice on writing the manuscript. 


\section{Author contributions}

Y.L.K. designed the study, prepared the data, analyzed data, wrote, and reviewed the paper. W.K. analyzed and interpreted data, wrote and reviewed the paper. S.K.P. analyzed data and reviewed the paper. All authors have read and agreed the published version of the manuscript.

\section{Competing interests}

The authors declare no competing interests.

\section{Additional information}

Supplementary Information The online version contains supplementary material available at https://doi.org/ 10.1038/s41598-021-03145-7.

Correspondence and requests for materials should be addressed to Y.L.K.

Reprints and permissions information is available at www.nature.com/reprints.

Publisher's note Springer Nature remains neutral with regard to jurisdictional claims in published maps and institutional affiliations.

Open Access This article is licensed under a Creative Commons Attribution 4.0 International License, which permits use, sharing, adaptation, distribution and reproduction in any medium or format, as long as you give appropriate credit to the original author(s) and the source, provide a link to the Creative Commons licence, and indicate if changes were made. The images or other third party material in this article are included in the article's Creative Commons licence, unless indicated otherwise in a credit line to the material. If material is not included in the article's Creative Commons licence and your intended use is not permitted by statutory regulation or exceeds the permitted use, you will need to obtain permission directly from the copyright holder. To view a copy of this licence, visit http://creativecommons.org/licenses/by/4.0/.

(C) The Author(s) 2021 